\title{
DISABLING AND DEFORMING CHRONIC TOPHACEOUS GOUT: IS IT POSSIBLE TO IMPROVE THE QUALITY OF LIFE AND FUNCTIONALITY WITH THE TREATMENT AVAILABLE IN BRAZIL? - A CASE REPORT
}

Clarice Moura Mata Machado ${ }^{1, \star}$, Letícia Neves Martins ${ }^{1}$, Matheus Fonseca Cardoso ${ }^{1}$, Rafael Fusaro Aguiar Oliveira ${ }^{1}$, Carolina Ruas Freire Santos ${ }^{1}$, Ricardo da Cruz Lage ${ }^{1}$, Rosa Weiss Telles ${ }^{1}$

1.Universidade Federal de Minas Gerais, Belo Horizonte (MG), Brazil.

*Corresponding author: claricematamachado@gmail.com

\section{BACKGROUND}

Gout is a disease caused by the deposition of monosodium urate crystals in joints, bones and soft tissues. It may result in acute arthritis, chronic arthritis and tophaceous gout, with bone erosions and joint destruction. Urate-lowering therapy aims to reach values lower than $6 \mathrm{mg} / \mathrm{dL}$ of serum urate, with even lower levels for chronic tophaceous gout ( $<5 \mathrm{mg} / \mathrm{dL}$ ), with the objective of improving quality of life and reducing functional, occupational and social incapacity.

\section{CASE REPORT}

This is a 66-year-old male patient with hypertension, type 2 diabetes, dyslipidemia, obesity, stage 3a chronic kidney disease and heart failure with preserved ejection fraction. Former alcoholic, with daily alcohol intake for 40 years, interrupting the habit in 2015. He was diagnosed with gout at age 34, but abandoned treatment after six months. He reported the appearance of tophi at age of 40 , with progressive worsening over the years, including recurrent secondary tophi infection, in addition to polyarthritis with disabling pain and chronic use of nonsteroidal anti-inflammatory, prednisone and opioids. He resumed follow-up with a rheumatologist in 2016, remaining in the same service since then. At the time, he presented large tophi on fingers, wrists, elbows, ears, knees, ankles, feet and buttocks (Figure 1), with pain and deformities that limited him to usual activities, including walking, remaining confined to bed or in a wheelchair. Joint radiography showed punched-out erosions, sclerotic overhanging edges, subcortical bone cysts and deformities. Treatment included aggressive measures to reduce serum urate (allopurinol at the maximum dose of 800 mg/day, and benzbromarone at the maximum dose of $100 \mathrm{mg} /$ day and treatment of hypertension with losartan $100 \mathrm{mg} / \mathrm{day}$ ), in addition to controlling acute flares with oral prednisone. The patient had good adherence to treatment and followed dietary recommendations. Despite all control measures, the occasionally therapeutic target of serum uric acid level achieved was never long-lasting (Figure 2). However, after approximately 5 years of continuous use of medications, there was an improvement in pain, a reduction in acute crises and a significant reduction in the volume of tophi (Figure 3), allowing the patient to walk again, improving functionality, quality of life and autonomy.

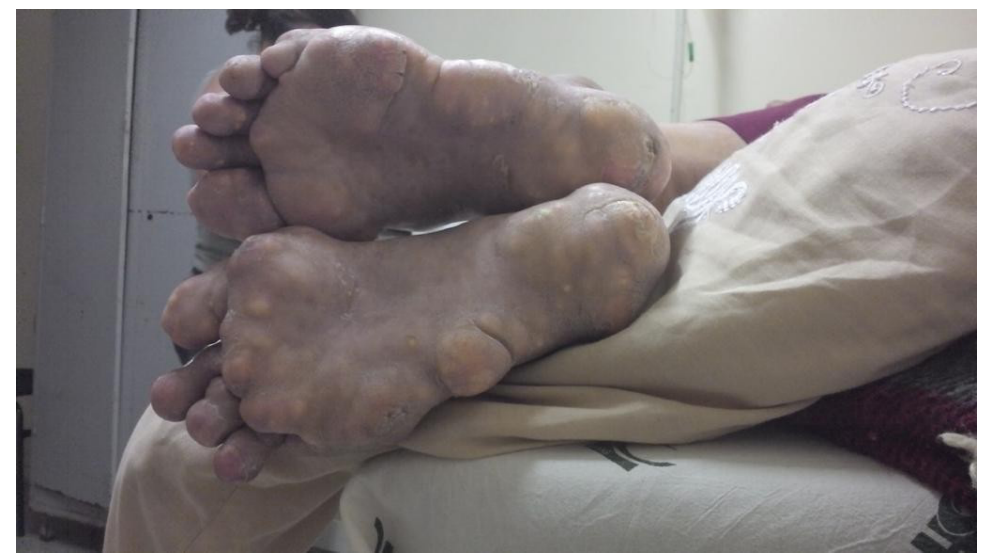

Figure 1. Large tophi on the feet, in 2016. 


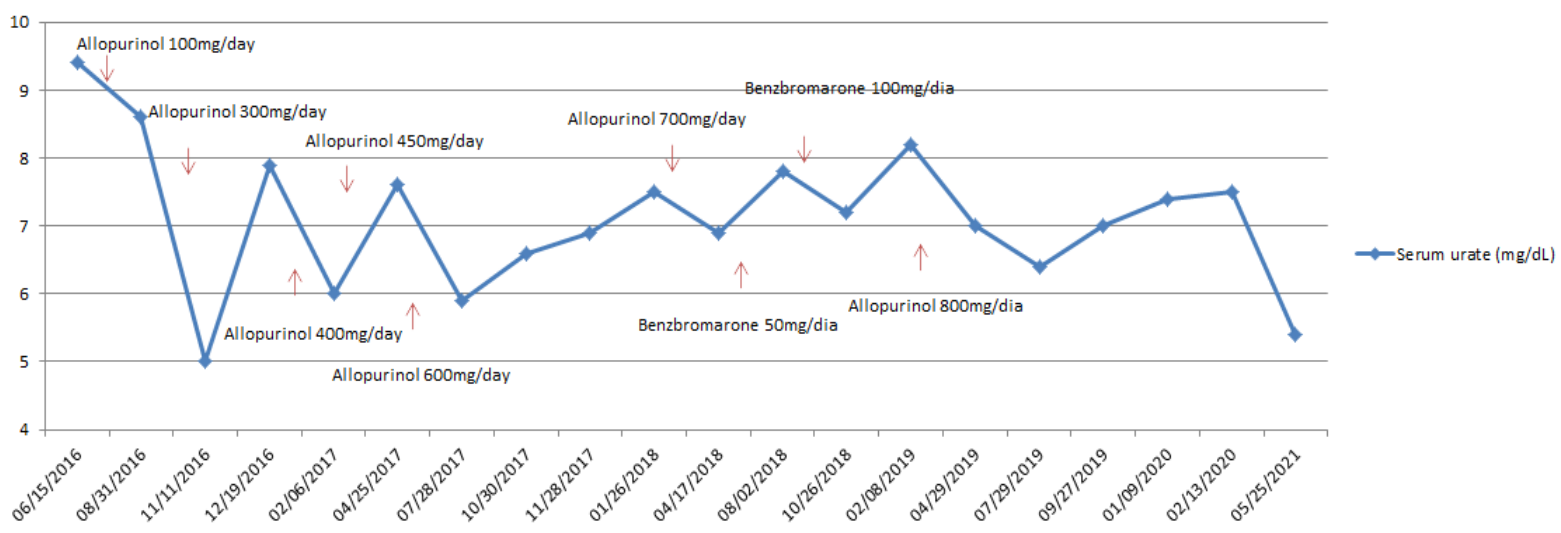

Figure 2. Evolution of serum urate levels and treatment interventions.

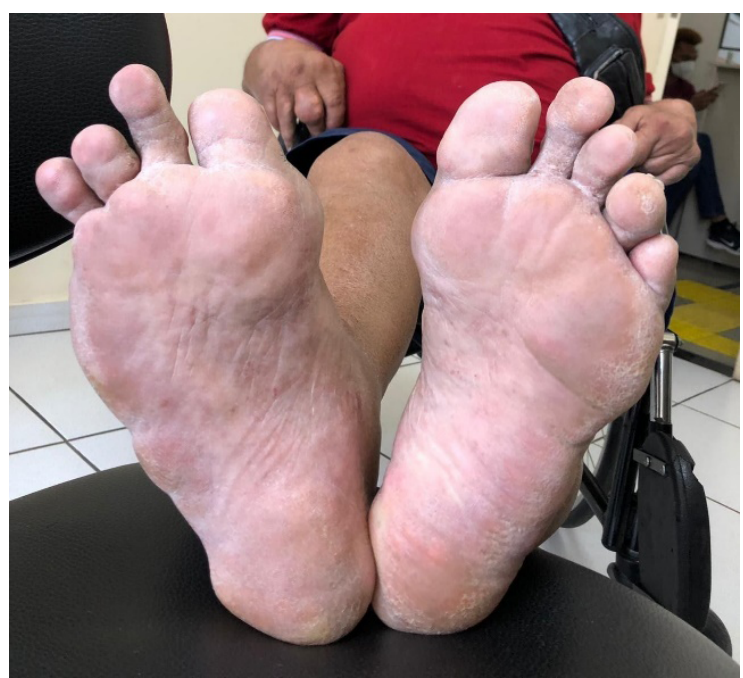

Figure 3. Improvement of tophi on the feet, in 2021.

\section{CONCLUSION}

This case portrays the importance of maintaining the urate-lowering therapy, even if, apparently, without success.

\section{KEYWORDS}

Gout, Tophi, Urate. 